\title{
Classification, soil-water characteristic curve and swelling/collapse behaviour of the Nicosia marl, Cyprus
}

\author{
Dimitrios Loukidis $^{1, a}$, Michael Bardanis ${ }^{2}$ and Georgia Lazarou ${ }^{1}$ \\ ${ }^{1}$ University of Cyprus, Civil \& Environmental Engineering Department, 75 Kallipoleos st., P.O. Box 20537, 1678 Nicosia, Cyprus \\ ${ }^{2}$ Edafos Engineering Consultants S.A., Laboratory, 2 Therapion st., 10444 Athens, Greece
}

\begin{abstract}
The city of Nicosia in the island of Cyprus is situated on a sedimentary basin, the surface layers of which are dominated by an expansive clayey soil called Nicosia marl. The high potential for volume change of this soil due to the seasonal changes of water content is the leading cause of foundation related damage to the buildings and infrastructure of the city. This paper presents preliminary results of a study focusing on the investigation of the Nicosia marl mechanical characteristics pertaining to moisture changes. Samples of Nicosia marl were collected from a borehole and a trial pit in the University of Cyprus campus. The pit which was subsequently used for installing an in-situ array of sensors monitoring suction and volumetric water content at depths inside the active zone. The SoilWater Characteristic Curve (SWCC) was measured in the laboratory for the entire range of degree of saturation. The potential of swelling/collapse at various values of vertical stress was studied through a series of oedometer tests.
\end{abstract}

\section{Introduction}

Expansive soils are responsible for damage to buildings and other civil engineering works, costing tens of billion dollars annually worldwide. Expansive clays cover wide areas of the island of Cyprus. They can be found throughout the Mesaoria basin between the Troodos and Kerynia mountain ranges and along the southern coastal region. Cyprus' climate is characterized by hot, dry summers and rainy winters. Buildings founded on the expansive soils of the island develop various types and degrees of damage due to expansion upon wetting during the winter months or due to water leakage from utility lines, as well as due to shrinkage in the summer months or due to transpiration caused by vegetation roots. In less severe cases, this damage may be limited to cracks on walls and other nuisance of architectural nature. In more extreme cases, soil expansion may even lead to failure of structural members.

This paper presents a preliminary experimental study of the physical and mechanical characteristics of the Nicosia marl, which is outcropping in most of the part of the central Mesaoria basin. The study focuses mainly on the properties pertaining to the volume expansion/ shrinkage associated to moisture changes, such as the soil-water characteristic (SWCC) curve and the swelling/collapse vs. vertical stress curve.

\section{Geological setting}

The Nicosia marl is a calcareous fine-grained soil belonging to the Nicosia geological formation, which has a thickness of several hundreds of meters. Nicosia marl is a marine sediment deposited during the Pliocene, when the Mesaoria basin was covered by a shallow sea. The Nicosia marl geological unit can be divided in two parts: the older grey marl and the more recent, overlying brown (khaki) marl [1]. The grey marl is the least expansive of the two. This study deals solely with the brown marl. The Nicosia marl is expansive because, although substantially calcareous, its montmorillonite content is significant and in certain parts of Nicosia reaches $25 \%$.

The location of the study is the new University of Cyprus (UCY) campus in the southeastern outskirts of Nicosia. The area is in the middle of the island of Cyprus, at a minimum distance of $20 \mathrm{~km}$ from the sea in any direction. Soil samples were collected from one borehole (drilled in May 2015) and one trial pit (excavated in July 2015) in a narrow zone where the Nicosia marl outcrops (excluding any thin top soil cover). Fig. 1 shows the surface geology of the UCY campus and the locations of the borehole (BH1) and pit (P1), which are $70 \mathrm{~m}$ apart and at an elevation of $137 \mathrm{~m}$. The northern part of the campus is a terrace, where the ground elevation steps to $140 \mathrm{~m}$ and the marl is covered by gravel cemented in a clay matrix (fanglomerate). In the southern part, the marl is covered by recent alluvial deposits (clayey sandy silt).

Fig. 2 shows the soil stratigraphy in the investigated area. The brown marl in the upper part of the profile is more sandy and stiffer than the marl found deeper than $5.5 \mathrm{~m}$. This is due to the higher percentage of calcium carbonate $\left(\mathrm{CaCO}_{3}\right)$ rather than overconsolidation or dessication. In fact, the $\mathrm{CaCO}_{3}$ content determined using Bernard calcimeter [2], is $46 \%$ for the samples taken

\footnotetext{
a Corresponding author: loukidis@ucy.ac.cy
} 


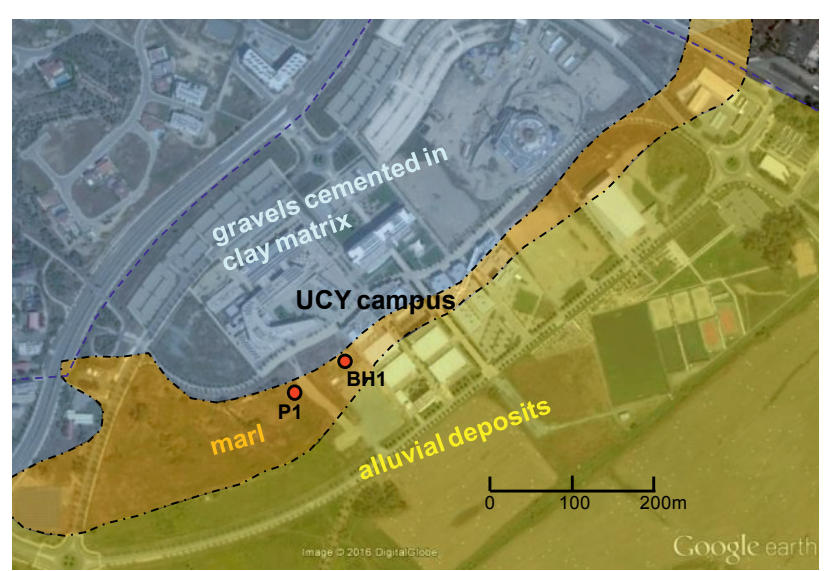

Figure 1. Simplified geologic map of the UCY campus area showing locations of sampling points ( $\mathrm{P} 1 \& \mathrm{BH} 1)$.

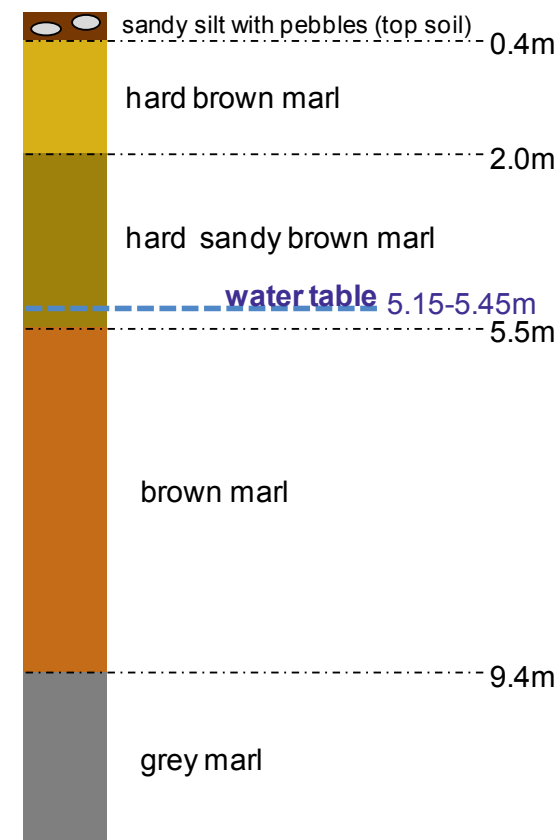

Figure 2. Simplified soil stratigraphy based on pit and borehole data.

from the trial pit (depth range 0.85 to $1.5 \mathrm{~m}$ ) and $43 \%$ at $4.5 \mathrm{~m}$ depth (borehole sample), while it is only $35 \%$ at $6 \mathrm{~m}$ depth (borehole sample). The underlying grey marl was encountered from $9.4 \mathrm{~m}$ depth to the bottom of the borehole at $36.5 \mathrm{~m}$ depth. Measurements from an opentype piezometer installed in BH1 show that the water table depth varies seasonally from $5.15 \mathrm{~m}$ to $5.45 \mathrm{~m}$, which roughly corresponds to an elevation consistent with a nearby creek further south (300m away).

\section{The recent experimental programme}

\subsection{Trial pit sampling and sensor installation}

One trial pit approximately $1.5 \mathrm{~m}$ deep and $2 \mathrm{~m}$ wide on either side was excavated in July 2015. The purpose of the trial pit was to obtain a clear view of the freshly excavated Nicosia marl, collect samples from the sides and the bottom of the pit, and install volumetric water content measurement sensors and porous blocks for suction measurement, for permanent monitoring of the seasonal fluctuations. The ground surface at the location of the pit is generally flat, sloping about $2^{\circ}$ to the south. Up to approximately $40 \mathrm{~cm}$ of top soil consisting of sandy silt with pebbles was found overlying the upper stiff brown Nicosia marl at the location of P1 (Fig. 3).

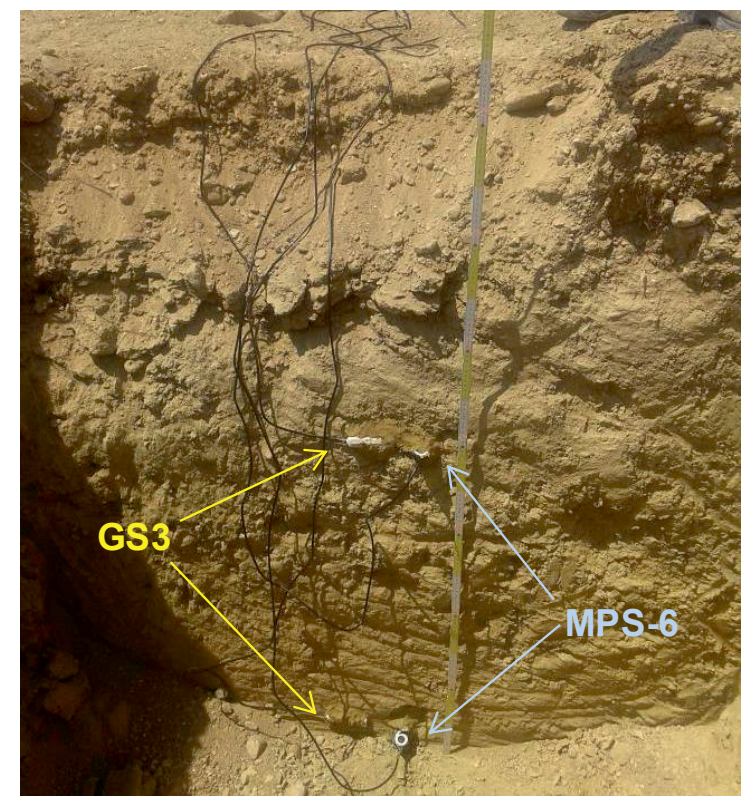

Figure 3. Western side of the trial pit excavated during July 2015, after installation of the sensors and before backfilling.

The samples taken were trimmed samples from the sides and bottom of the trial pit, and an intermediate bench created at $0.85 \mathrm{~cm}$ depth. These samples were protected by wrapping in cling film and plastic bags. In addition, undisturbed samples were taken using steel tube samplers, the ends of which were covered with molten paraffin wax. The sensors installed were the GS3 frequency domain reflectometry (FDR) volumetric water content sensor and the MPS-6 porous block FDR sensor measuring matric suction, both by Decagon Devices, Inc. A pair of sensors of each type were installed at a depth of $0.75 \mathrm{~m}$ and another one at $1.5 \mathrm{~m}$. Fig. 3 shows the western side of the trial pit after installation of the sensors, before backfilling and compacting the pit. Care was taken in using for backfill as much as possible of the excavated material, targeting in having final density in the backfill similar to that of the undisturbed marl. The installed sensors, which are connected to an automatic Em50 data logger (Fig. 4) and measure continuously, are expected to shed light in the future into the seasonal variation of suction and volumetric water content in the Nicosia marl inside the active zone.

\subsection{Index properties and classification}

The properties from soil classification tests are summarised in Table 1. Nicosia marl at shallow depths (trial pit) was found in the form of a light brown very stiff material. USCS classification varied between CL and $\mathrm{CH}$, i.e. clay of either low or high plasticity. On average, the liquid limit was $47.6 \%$, the plasticity index $\left(\mathrm{I}_{\mathrm{p}}\right) 23.2$ 


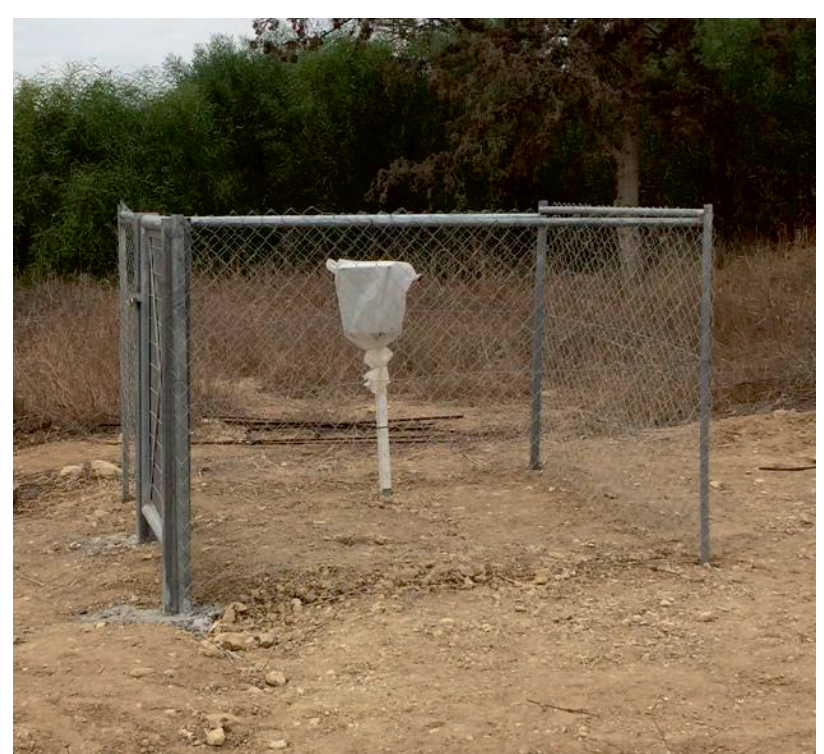

Figure 4. Trial pit backfilled and fenced to protect the sensor data acquisition box.

Table 1. Index properties and classification of Nicosia marl from samples taken during the 2015 geotechnical investigation.

\begin{tabular}{|c|c|c|c|c|c|c|}
\hline Sample & $\begin{array}{c}\text { clay } \\
(\%)\end{array}$ & $\begin{array}{c}\text { silt } \\
(\%)\end{array}$ & $\begin{array}{c}\mathbf{W}_{\mathbf{L}} \\
(\mathbf{\%})\end{array}$ & $\mathbf{I}_{\mathbf{P}}$ & $\mathbf{G}_{\mathbf{s}}$ & $\mathbf{U S C S}$ \\
\hline 1 (pit) & 20.3 & 62.4 & 53.9 & 28.8 & 2.69 & $\mathrm{CH}$ \\
\hline 2 (pit) & 20.5 & 62.7 & 52.3 & 25.4 & 2.68 & $\mathrm{CH}$ \\
\hline 3 (pit) & 24.5 & 62.5 & 44.9 & 19.4 & 2.66 & $\mathrm{CL}$ \\
\hline 4 (pit) & 16.3 & 61.6 & 39.2 & 19.1 & 2.72 & $\mathrm{CL}$ \\
\hline $\begin{array}{c}\text { BH1 } \\
\text { 6m }\end{array}$ & 30 & 60 & 65.6 & 35.5 & 2.68 & $\mathrm{CH}$ \\
\hline
\end{tabular}

and the specific gravity $\mathrm{G}_{\mathrm{s}}$ 2.685. The water content ranged from $10 \%$ to $14 \%$ and the dry unit weight from 14.7 to $16.0 \mathrm{kN} / \mathrm{m}^{3}$. Particle size distribution tests showed that, on average, the clay-size fraction was $20.4 \%$, siltsize fraction $62.3 \%$, and fine sand $17.3 \%$ (only traces of medium and coarse sand were measured). The sand content of the borehole samples of brown marl below $5.5 \mathrm{~m}$ depth is even smaller. Organic content was present in all trial pit samples, on average found to be $2.4 \%$. The latter is not considered to be a generally observed property of the Nicosia marl formation, but it certainly exists in samples coming from shallow depths as in the case of the trial pit. One linear shrinkage test was performed on Sample 1 yielding a value of $12.6 \%$.

Based on the data shown in Table 1, the potential expansiveness of the shallow hard brown marl samples from the trial pit ranges from medium to high according to the South African chart $[3,4]$. On the other hand, the softer brown marl found at $6 \mathrm{~m}$ depth is categorized as very highly expansive based on the same chart. The profile of degree of saturation $S_{r}$ in the summer of 2015 can be seen in Fig. 5, plotted using data from both the trial pit and the borehole. The marl was found to be fully saturated at $3 \mathrm{~m}$ depth, $1.45 \mathrm{~m}$ above the water table. In the depth range of the trial pit, the marl has a degree of

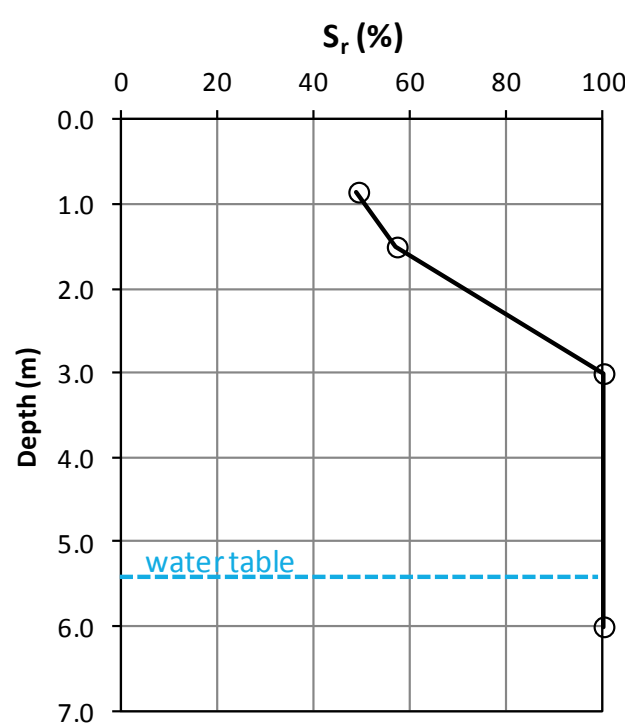

Figure 5. Profile of degree of saturation in July 2015.

saturation around $50 \%$. Hence, the active zone in the region of the study appears to be 2 to $3 \mathrm{~m}$.

\subsection{Hydraulic conductivity}

The hydraulic conductivity of two Nicosia marl samples, one from the bench of the trial pit $(0.85 \mathrm{~m}$ depth) and one from the borehole at $6 \mathrm{~m}$ depth was determined in a triaxial cell (flexible wall permeameter) [5]. The specimens $(3.5 \mathrm{~cm}$ diameter, $7 \mathrm{~cm}$ height) were first back pressure saturated (a back pressure of $800 \mathrm{kPa}$ was needed to reach B-values larger than 0.95 ) and then consolidated to a mean effective stress $p^{\prime}=120 \mathrm{kPa}$ for the pit sample and $90 \mathrm{kPa}$ for the borehole sample, before applying various hydraulic gradients ranging from 15 to 31 . The coefficient of hydraulic conductivity $k$ of the shallow hard marl (pit) was $2.6 \times 10^{-7} \mathrm{~cm} / \mathrm{s}$, while for the softer marl at depth turned to be smaller and equal to $9.8 \times 10^{-8}$ $\mathrm{cm} / \mathrm{s}$, despite having an initial void ratio of 0.79 $\left(\gamma_{\mathrm{d}}=14.7 \mathrm{kN} / \mathrm{m}^{3}\right)$, much higher than that of the hard marl $(\mathrm{e}=0.67)$. This is due to the fact that the shallow hard marl is less plastic and less clayey and has experienced desiccation cycles in its geological history.

\subsection{One-dimensional compression}

An one-dimensional compression test was performed on a trial pit sample in a conventional $15 \mathrm{kN}$ capacity pneumatic oedometer, but with a modified $30 \mathrm{~mm}$ diameter cell. The height of the sample was $15 \mathrm{~mm}$ in order to keep a diameter to height ratio of 2 . The cell has a fixed ring of smooth inner surface slightly lubricated prior to the test. The one-dimensional compression curve for the particular sample $\left(\mathrm{w}_{\mathrm{L}}=53.9 \% / \mathrm{I}_{\mathrm{p}}=28.8\right)$ is shown in Fig. 6 along with the Casagrande graphical method for yield stress determination. The yield stress according to this method was found to be $3.3 \mathrm{MPa}$, indeed a very high value even if one takes into account the cementation of the particular marl and its initial partial saturation at the 


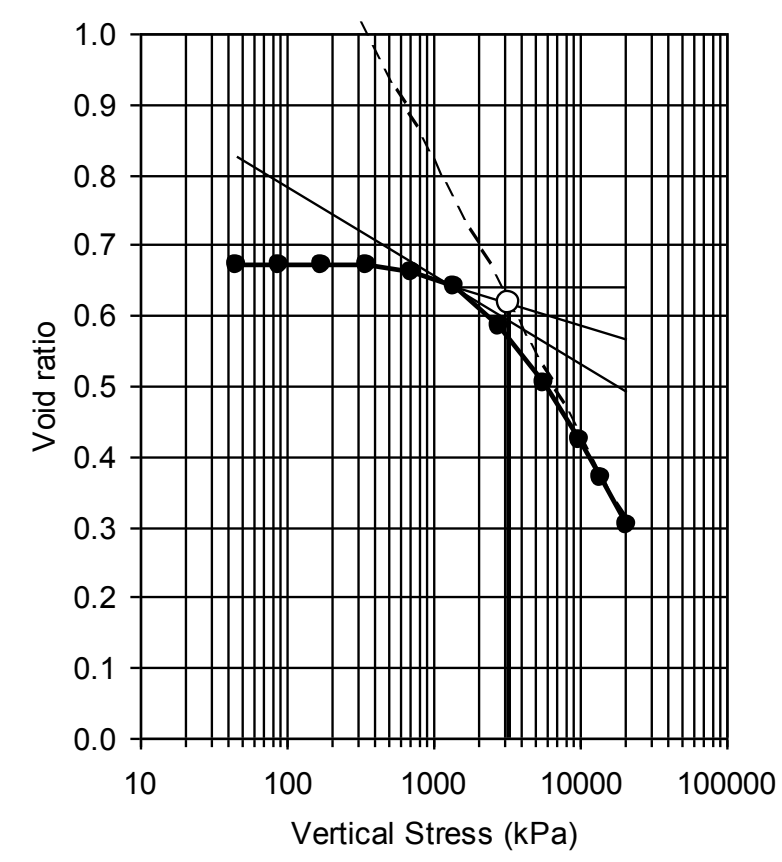

Figure 6. One-dimensional compression curve of hard Nicosia marl (pit sample) up to $21.2 \mathrm{MPa}$ of vertical stress with the Casagrande graphical method for yield stress estimation.

beginning of the test. A compression index value of 0.39 was obtained from the tangent of the post-yield linear part of the one-dimensional curve in the semi-logarithmic plot between 9.9 and 21.2MPa.

\subsection{Swelling/collapse under one-dimensional conditions}

A series of swelling/collapse tests were performed using conventional $15 \mathrm{kN}$ capacity pneumatic oedometers. Specimens were trimmed from the larger samples obtained from the trial pit, placed on the oedometers and subjected to various values of constant vertical stress. Once the observed deformations had ceased the samples were inundated and the deformation due to inundation were measured. The strains calculated from these tests are plotted against vertical stress in Fig. 7. The vertical stress corresponding to zero deformation upon inundation was $85 \mathrm{kPa}$, a relatively small value that in the particular occasion could not have caused any alarm in foundation engineering practice, although it is associated with significant swelling strain for lower vertical stress, such as those applied by mat foundations, and similarly significant collapse strain for higher vertical stress.

Swelling/collapse tests were also performed on specimens of compacted brown marl obtained from $6 \mathrm{~m}$ depth, which is more plastic and expansive than the marl encountered in the trial pit. The specimens were compacted at various values of initial dry unit weight $\gamma_{\mathrm{d}}$ and degree of saturation $\mathrm{S}_{\mathrm{r}}$. Fig. 8 shows the result of this series of tests, grouped in ranges of $\gamma_{d}$ and $S_{r}$. As observed in previous studies [6,7], the tendency of expansion increases with increasing initial $\gamma_{d}$ and decreasing initial $\mathrm{S}_{\mathrm{r}}$. Moreover, the expansiveness seems to be much more sensitive to the initial dry unit weight than the degree of saturation. (a) Vertical Stress $(\mathrm{kPa})$ 0 100 200 300

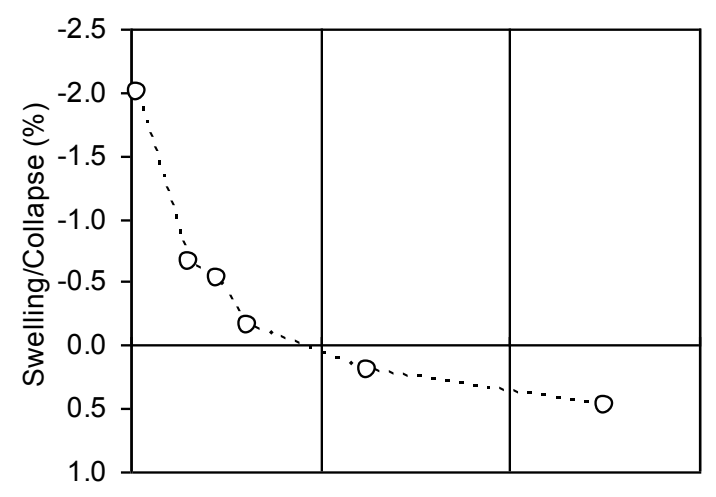

(b)
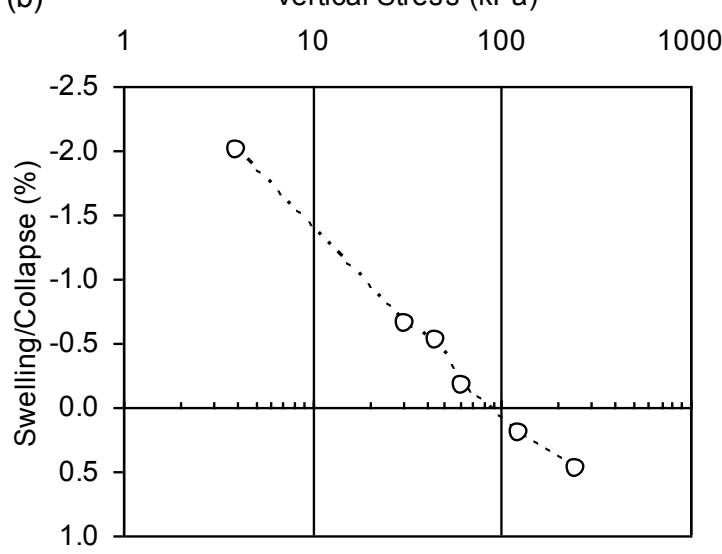

Figure 7. Strain due to inundation versus vertical stress for hard Nicosia marl (pit samples) as a function of applied constant vertical stress in a) linear scale, and b) logarithmic scale.

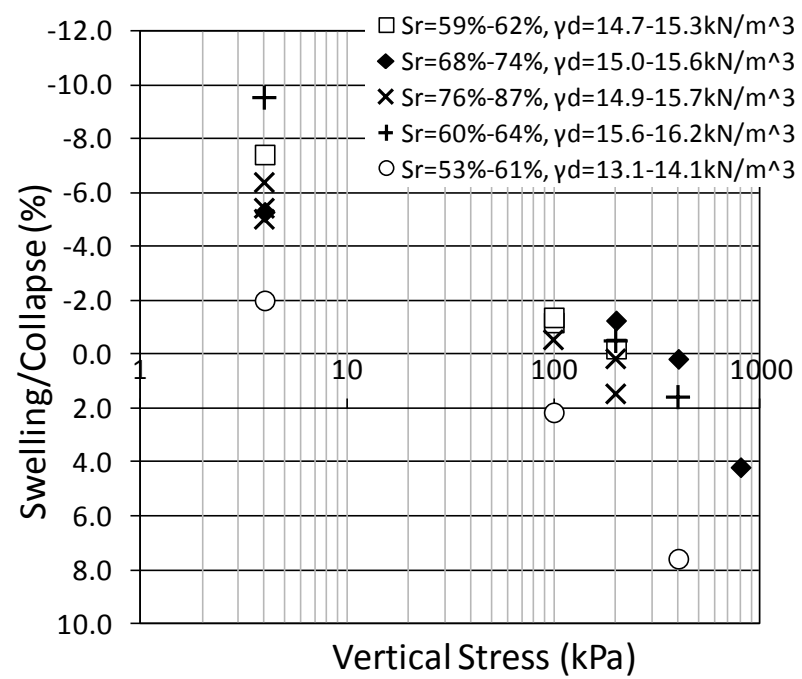

Figure 8. Strain due to inundation versus vertical stress for compacted brown Nicosia Marl sampled from $6 \mathrm{~m}$ depth as a function of vertical stress.

For the initial states tested in this series, the vertical stress corresponding to zero deformation upon inundation ranges from $12 \mathrm{kPa}$ to $200 \mathrm{kPa}$ and the "free" swelling strain (swelling at vertical stress of $4 \mathrm{kPa}$ ) from $2 \%$ to $9.5 \%$. As in Fig. 7b, the swelling/collapse versus vertical stress loci could be approximated by straight lines, which 
appear to have roughly the same inclination, provided that the horizontal axis is in logarithmic scale.

\subsection{Soil-water characteristic curve (SWCC)}

Suction was measured on the sides of the trial pit and in the samples taken and brought to the laboratory. The use of Soilmoisture Equipment Corp. Quickdraw field tensiometer and $2100 \mathrm{~F}$ laboratory tensiometer revealed suction values higher than $90 \mathrm{kPa}$; in fact much higher given the rate of desaturation of the porous ceramic tips of both instruments. The Decagon Devices, Inc. chilled mirror hygrometer was therefore used and total suctions between 5.4 and $8.7 \mathrm{MPa}$ were measured (Fig. 9). This was a remarkable finding corresponding to very high values of suction (even if the anticipated osmotic component were subtracted from the values measured with the chilled mirror hygrometer which measures total suction). The trial pit was opened in July 2015, a very dry and hot season in the area. The block samples taken were protected by cling film and plastic bags and tube samples were sealed with molten paraffin wax. Although there was concern at the beginning that the samples covered only with cling film and plastic bags may dry until they are brought in the laboratory, the highest suction was actually measured in an undisturbed sample from tube sampler and covered with paraffin wax, indicating thus that the values measured were little affected by drying.

After initial suction measurements, several samples were left to dry in order to measure the rest of the drying portion of the SWCC, and others were gradually wetted in order to measure (at least part of) the wetting portion of the soil-water characteristic curve from the particular initial conditions. Drying was applied by leaving samples in the atmospheric conditions of the laboratory, then sealing them for equilibrium of moisture conditions throughout the samples, and then unsealing them for suction measurement using the chilled mirror hygrometer and total volume measurement using immersion in molten paraffin wax. For comparison, some samples were dried by placing them in controlled relative humidity chambers using saturated salt solutions $[8,9]$ of $\mathrm{BaCl}_{2}$, $\mathrm{KCl}, \mathrm{NaCl}, \mathrm{Mg}\left(\mathrm{NO}_{3}\right)_{2}$ and $\mathrm{MgCl}_{2}$. No difference was observed between the two methods; the salt solutions method allows though for targeted and more controlled values of applied total suction.

The soil-water characteristic curves obtained are shown in Fig. 9 and the shrinkage curves in Fig. 10. The combination of suction, water content, degree of saturation and void ratio position the material, in its initial state, close to the residual void ratio branch of the shrinkage curve (Fig. 10a) and the soil-water characteristic curve expressed in terms of void ratio versus suction (Fig. 9c). The material can certainly dry more as exhibited by the drying portions from the natural state of the soil-water characteristic curve, as shown in Fig. 9a,b. Still it is highly unlikely that the material could really shrink more, as exhibited by the drying portions from the natural state of the soil-water characteristic curve as shown in Fig. 9c and 10a. Consequently, the drying portion from the natural state of the shrinkage
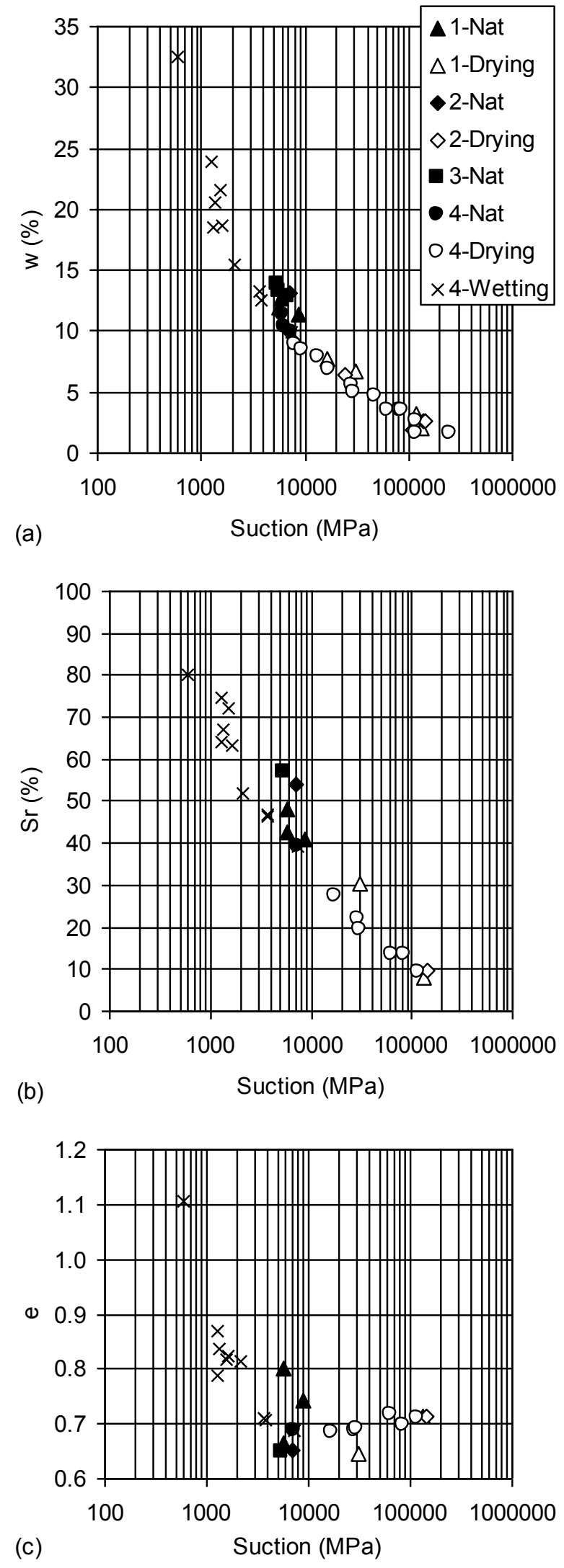

Figure 9. Soil-water characteristic curve of hard Nicosia marl in terms of a) water content, b) degree of saturation, and c) void ratio against suction. Filled points correspond to the natural state, empty points to drying from the natural state, and crosses to wetting from the natural state. 

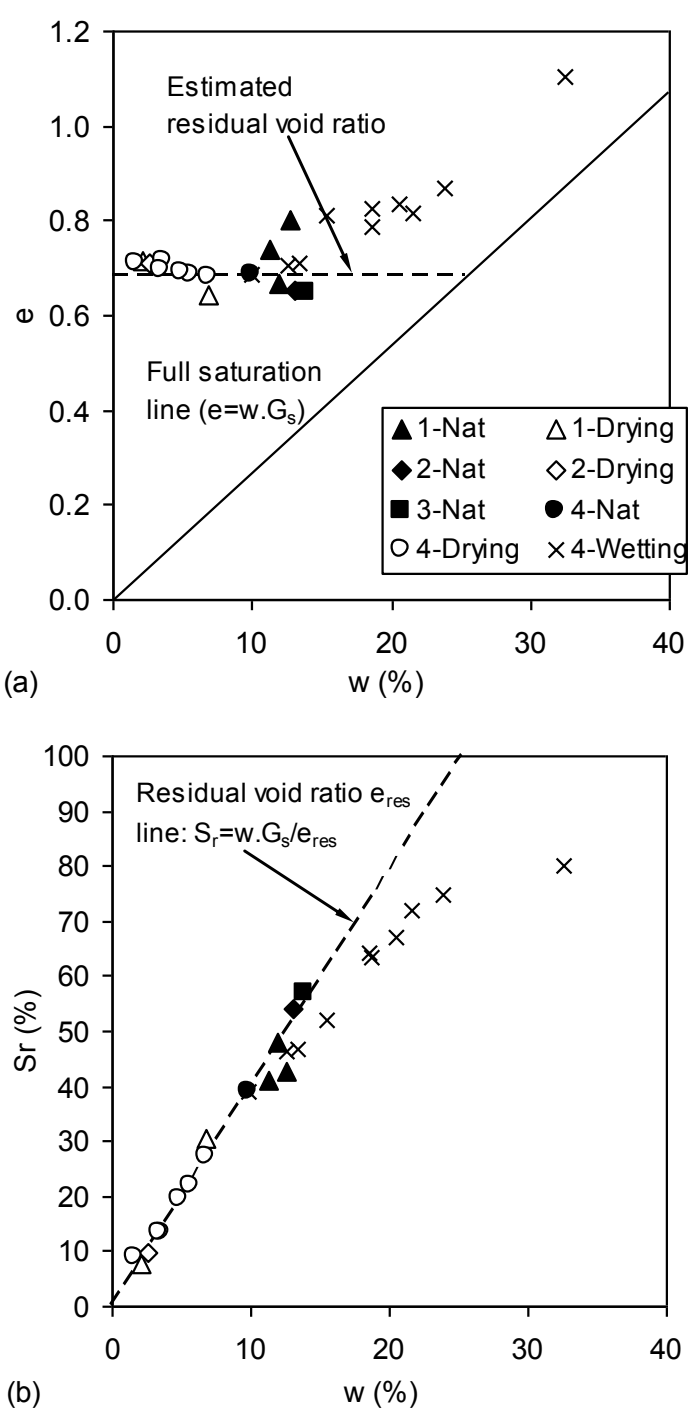

Figure 10. Shrinkage curve of Nicosia Marl in terms of a) void ratio versus water content, and b) degree of saturation versus water content. Filled points correspond to the natural state, empty points to drying from the natural state, and crosses to wetting from the natural state.

curve expressed in terms of degree of saturation versus water content in Fig. 10b lies on the residual void ratio line $\left(\mathrm{S}_{\mathrm{r}}=\mathrm{w}_{\mathrm{v}} \cdot \mathrm{G}_{\mathrm{s}} / \mathrm{e}_{\mathrm{res}}\right)$, corresponding to an average residual void ratio, $e_{\text {res }}$, of 0.68 and the average $G_{s}$ value of 2.685. Given the very high values of suction in the material in its natural state at the time of sampling, the first inflection point of the soil-water characteristic curve was not observed and the second inflection point seems to lie close to the natural state itself (filled points in Fig. 9).

Regarding wetting from the natural state, this was achieved by gradual addition of water to the samples, trimmed from the larger block samples from the trial pit. These samples were again sealed for equilibrium and then unsealed for suction measurement using the chilled mirror hygrometer and total volume measurement using immersion in molten paraffin wax. The material yielded large increases of void ratio (in fact without even complete extinction of suction). It is of interest that even at the highest value of water content during rewetting $(32.5 \%)$ the soil did not obtain full saturation with the experimental point lying at considerable distance from the full saturation line in Fig. $10 \mathrm{a}$ and the $\mathrm{S}_{\mathrm{r}}=100 \%$ line in Fig. 10b. The measured value of total suction using the chilled mirror hygrometer at this moisture condition was $600 \mathrm{kPa}$. Even if we assume very high values of the osmotic suction component, such a high value of total suction cannot correspond to zero matric suction.

\section{Conclusions}

The findings of a preliminary study on the physical and mechanical characteristics of the expansive Nicosia marl were presented. The soil water characteristic curve and shrinkage curves were determined. A series of oedometer tests were performed in order to explore the potential for swelling/collapse upon inundation as a function of the applied vertical stress.

Total suction values inside the active zone during summer are very high (several MPa in magnitude). The natural state of the Nicosia marl at shallow depths was found to be very close to its residual void ratio. The Nicosia marl has a relatively large potential for expansion or collapse despite a relatively low swelling pressure that seldom exceeds $200 \mathrm{kPa}$. Finally, the potential of expansion for a given soil is more sensitive to the values of initial dry unit weight than to the initial degree of saturation.

\section{Acknowledgements}

The authors would like to thank the personnel of the Technical Services of the University of Cyprus for their support in field work and making available previous geotechnical investigation data. EDAFOS S.A. laboratory technicians $\mathrm{Mr} \mathrm{Ch}$. Vagenas and $\mathrm{Mr}$ M. Tsoukaladakis assisted with testing.

\section{References}

1. G. Constantinou, I. Panagides, K. Xenophontos, S. Afrodisis, P. Michaelides, S. Kramvis, The geology of Cyprus (Bulletin No. 10, Cyprus Geological Survey, 2002)

2. J. Hulseman, J. of Sedimentary Petrology, 36, 622625 (1966)

3. D.H. Van der Merwe, Proc. $6^{\text {th }}$ Reg. Conf. Africa on Soil Mech. and Found. Engin., Vol. 2, 166-167 (1975)

4. A.A. Williams, G.W. Donaldson, Expansive Soils, 834-844 (1980)

5. K.H. Head, R.J. Epps, Manual of Soil Laboratory Testing, Volume III: Effective Stress Tests (Whittles Publishing, 2014)

6. H. Komine (2004). Engin. Geol., 71, 265-279 (2004)

7. O. Buzzi, S. Fityus, A. Giacomini. Géotechnique, 61, 271-277 (2011)

8. D.G. Fredlund. Proc. $3^{\text {rd }}$ Int. Conf. on Unsat. Soils, 20-23 (2002)

9. A.M. Tang, Y.J. Cui. Canadian Geot. J., 42, 287-296 (2005) 